\title{
CONGENITAL CHYLOTHORAX: CURRENT EVIDENCE-BASED PRENATAL AND POST-NATAL DIAGNOSIS AND MANAGEMIENT
}

\author{
L.C. De Angelis, T. Bellini, M.H. Witte, R.I. Kylat, M. Bernas, F. Boccardo, D. Paladini, \\ G.M. Magnano, L.A. Ramenghi, C. Bellini
}

Department Mother \& Child, Neonatal Intensive Care Unit (LCDA,TB,LAR,CB) and Fetal Medicine \& Surgery Unit (GMM), IRCCS Istituto Gaslini, Genova, Italy; Departments of Surgery (MHW) and Pediatrics (RIK), University of Arizona College of Medicine, Tucson, Arizona, USA; Department of Medical Education (MB), TCU and UNTHSC School of Medicine, Fort Worth, Texas, USA; Department of Surgery (FB), University of Genova, Italy; Radiology Department (DP), IRCCS, Istituto Giannina Gaslini, Genova, Italy

\section{ABSTRACT}

Congenital chylothorax is an uncommon condition but represents the main cause of congenital pleural effusion during the neonatal period. It usually appears before birth, both as an isolated disorder or in association with hydrops fetalis, negatively affecting the subsequent neonatal outcome. Prenatal treatment is usually considered to ensure a satisfactory lung development in case of moderate to severe pleural effusion or in the presence of hydrops, although consensus on treatment timing and modalities has not been reached to date. Both medical and surgical therapeutic strategies are available to treat this condition and novel treatment options have been recently attempted with acceptable results in both prenatal and post-natal setting. The heterogeneous clinical presentation of congenital chylothorax together with its rarity, its numerous etiologies and the absence of a highly effective treatment renders the diagnostic and therapeutic approach difficult to standardize. In addition, adequate visualization of the lymphatic system is complex, especially in small neonates, although new promising techniques have been developed lately and may contribute to improved management of this serious but infrequent condition. This review focuses on the current evidence base for the diagnosis and treatment options for congenital chylothorax, suggesting a rational diagnostic and therapeutic approach both in the prenatal and in the neonatal period.

Keywords: congenital chylothorax, hydrops, fetal hydrothorax, lymphatic system, diagnosis, evidence-based management

\section{CONGENITAL CHYLOTHORAX}

Congenital chylothorax consists of a lymphatic fluid accumulation within the pleural space, which can occur prenatally or during the neonatal period (1). Lymph originates in the interstitial spaces within organs and is composed of cells, particles, lipids, proteins and peptides (2). Flowing into progressively larger lymphatic vessels and passing through one or more regional lymph nodes (3), lymphatic fluid reaches the cisterna chyli located between the aorta and the vena cava. Then it enters the thoracic duct located in the posterior right mediastinum between the aorta and the azygos vein, crosses the aortic arch and eventually reaches the blood circulation between the jugular and the left subclavian veins. 
Any pathologic process that causes damage or obstruction to the lymphatic system may lead to a leakage of lymph, which can variably fill the pleural space or the peritoneal cavity causing chylous ascites. Whereas congenital chylothorax is a rare condition, it represents the most common cause of congenital pleural effusion during the neonatal period (4). The reported incidence of congenital chylothorax is about $0.4-1.7: 10,000$ live births with a male:female ratio of $2: 1(5,6)$. It is often bilateral, but the right side is more frequently involved due to the usual localization of the thoracic duct largely in the right mediastinum. Congenital chylothorax is caused either by anomalies in lymphatic development or other conditions that affect the structure and/or function of the lymphatic system, leading to chylous fluid leakage (7-9). Though in some cases a specific cause is not found, congenital chylothorax has been associated with genetic syndromes in which a degree of lymphatic dysplasia is present and with congenital anomalies involving the thoracic region (1014). Main conditions associated with congenital chylothorax are shown in Table 1.

\section{CLINICAL FEATURES AND PROGNOSTIC FACTORS OF CONGENITAL CHYLOTHO- $R A X$}

Most cases of congenital chylothorax are diagnosed during pregnancy, more frequently during the third trimester (15). As the fetus is not fed in utero and the mean percentage of blood lymphocytes is normally $>80 \%$, congenital chylothorax is rather called "hydrothorax" prenatally (16).

When occurring early during fetal development it may have detrimental consequences on lung growth, leading both to pulmonary hypoplasia and to pulmonary hypertension. In addition, the mass effect caused by the pleural effusion may compromise venous return, causing cardiac failure $(17,18)$.

In case of massive lymph effusion hydrops fetalis may develop (4), and this condition is associated with fetal demise in a large pro-

\section{TABLE 1}

Conditions Associated with Anatomical or Functional Anomalies of the

Lymphatic Drainage System, Which can Result in Congenital Chylothorax

\section{Conditions associated with} congenital chylothorax

\section{Anomalies of the lymphatic system}

Mediastinal lymphangioma

Congenital pulmonary lymphangiectasia

Lymphatic dysplasia syndrome

Congenital atresia of the lymphatic duct

Intestinal lymphangiectasia

\section{Thoracic anomalies}

Congenital pulmonary malformations

Congenital diaphragmatic hernia

H-type tracheoesophageal fistula

Mediastinal tumors or cysts

Congenital heart defects

Superior vena cava obstruction

Bilateral agenesis of superior vena cava

\section{Genetic syndromes}

Noonan's syndrome

Trisomy 21

Turner syndrome

Ehlers Danlos disease

X-linked myotubular myopathy

Hennekam syndrome

Missense mutation in integrin $\alpha 9 \beta 1$

Gorham-Stout syndrome

Yellow nail syndrome

portion of cases especially if diagnosed during early pregnancy (19). The natural history of congenital hydrothorax is extremely variable. Spontaneous regression has been reported in $22 \%$ of cases, with a nearly $100 \%$ survival rate (20), while severe conditions, mostly when associated with hydrops, may lead to high morbility and mortality (21). Poor prognosis is related to bilateral pleural effusion, hydrops, polyhydramnios, progressive fluid accumulation with mediastinal shift and early gestational age at diagnosis (less than 30 weeks of gestational age) (22-25). Prenatal treatment has been shown to improve neonatal survival 
significantly in fetuses with hydrops or progressive effusion (26), yet perinatal mortality remains high, varying between $22 \%$ and $53 \%$ (27).

Neonates with congenital chylothorax often show respiratory distress at birth due to lung hypoplasia and/or due to premature birth associated with prenatal intervention (28). Poor cardiovascular function and generalized edema may be present in more severe cases, and percutaneous evacuation of chyle is associated with fluid, protein including immunoglobulin and $\mathrm{T}$ lymphocyte depletion, which increases the risk of neonatal infections $(29,30)$.

\section{PRENATAL DIAGNOSIS OF CONGENITAL CHYLOTHORAX}

Diagnosis of fetal hydrothorax is made when a monolateral or bilateral pleural effusion is detected by ultrasound (Fig. 1).

In the case of two or more fluid collections, including ascites, pleural or pericardial effusion, and generalized subcutaneous edema, a diagnosis of hydrops should be made (31). Fetal primary hydrothorax is caused by an anomalous development of the lymphatic system, while secondary forms are associated with a number of conditions characterized by an imbalance in the regulation of fluid movements between the blood vascular space and the interstitium (32) (Fig. 2).

Once a pleural effusion is detected, a comprehensive prenatal evaluation is necessary to determine the etiology, predict the prognosis and establish a treatment strategy. A diagnostic work-up of fetal hydrothorax is presented in Table 2 (33).

\section{MANAGEMENT OF PRENATAL CONGEN- ITAL CHYLOTHORAX}

Once other causes of secondary pleural fluid effusion are excluded, treatment of fetal primary hydrothorax should be considered in utero in order to decompress the pleural space and reduce the intrathoracic pressure, restor-

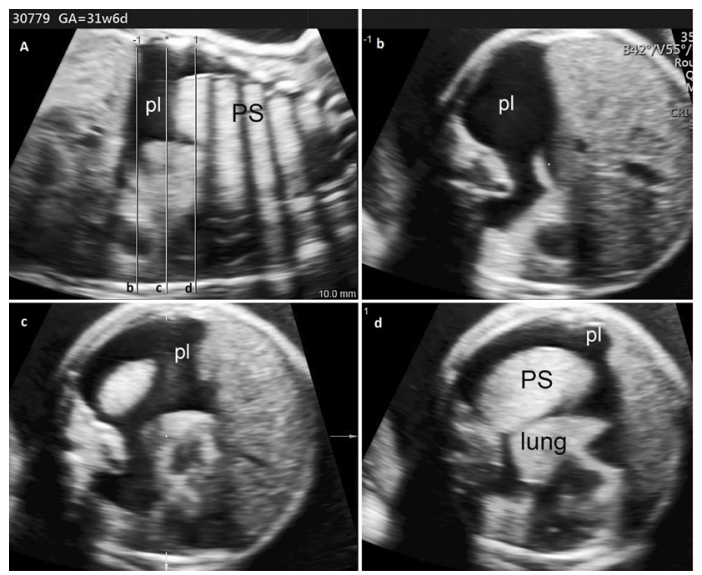

Fig. 1. Pulmonary sequestration complicated by severe hydrothorax in a 31+6 weeks fetus. A: sagittal section showing right hydrothorax (pl) associated with a large pulmonary extra-lobar sequestration (PS). Downward displacement of the diaphragm caused by the effusion is noted. Plane section levels $b, c$ and $d$ are shown; $b, c$ : evidence of pl in transversal sections; d: upper transverse section showing PS, severe hydrothorax, and compressed right lung.

ing normal lung development and fetal hemodynamics (34). Fetal intervention has been associated with a higher survival of preterm infants with congenital chylothorax (35), and it increased Apgar scores, reduced ventilator days, and decreased complications in neonates with hydrops fetalis (36). Lack of consensus exists on what is the preferable therapeutic strategy in these patients as no randomized studies have been conducted to date due to the rarity of this condition and the marked heterogeneity of the disease. Gestational age, severity, and progression of pleural effusion and concomitant presence of secondary fetal consequences (e.g. hydrops, pulmonary hypoplasia, mediastinal shift) are usually considered to decide on the best treatment option (37). Conservative management and close follow-up with serial ultrasounds should be considered in case of small to moderate unilateral effusion without hydrops, as spontaneous resolution may occur (26). Conversely, in case of large or progressive pleural effusion or hydrops, prenatal interventions include thoracocentesis (either single or repeated) (17), pleuroamniotic 


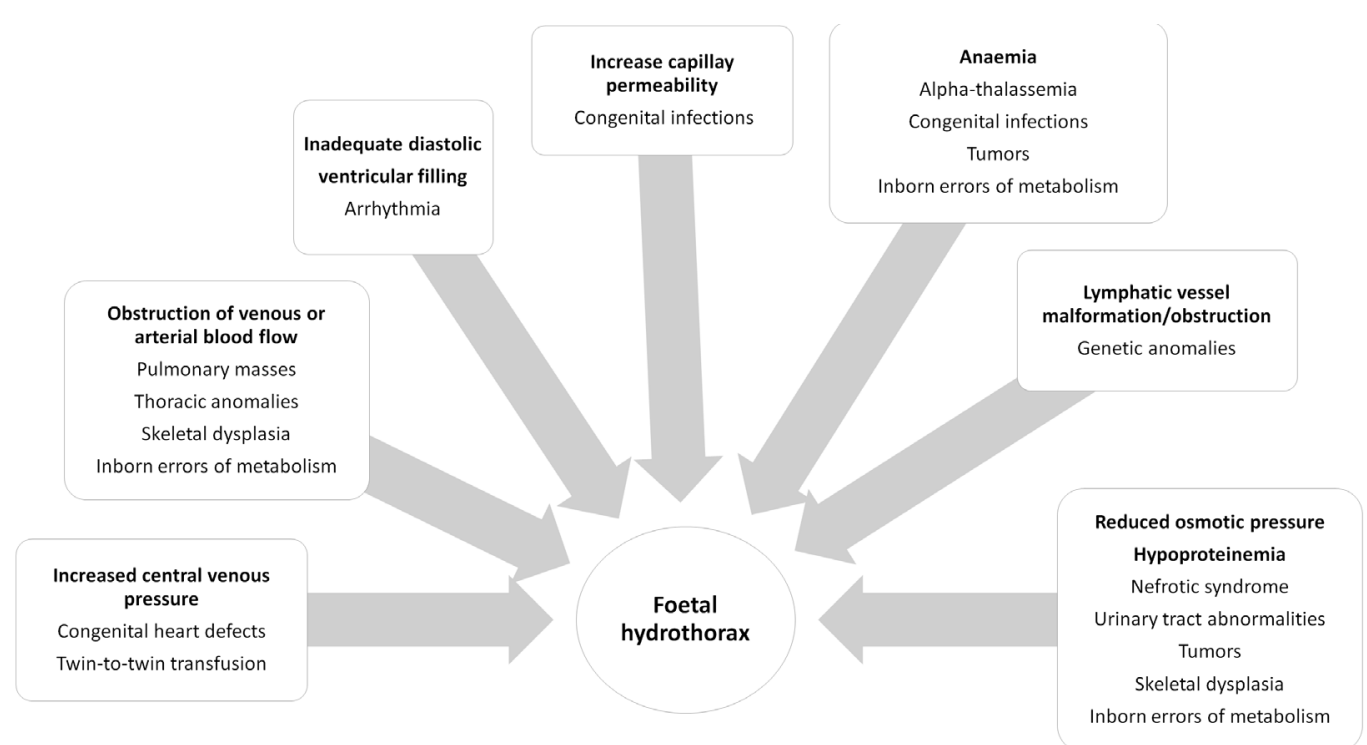

Fig. 2. Pathological conditions associated with the development of fetal hydrothorax.

shunting $(38,39)$ and intrauterine pleurodesis with OK-432 (40). In addition, in case of polyhydramnios, multiple amniodrainage may be considered (41). Thoracocentesis is often performed as initial treatment but in most cases a rapid fluid re-accumulation is observed and repeated thoracocentesis or pleuroamniotic shunt becomes necessary. Decompression of thoracic structures following thoracocentesis has both therapeutic and diagnostic value: it may reveal pulmonary hypoplasia in case of failed lung expansion and may improve heart defect detection once the mediastinum returns to a correct position (42). As the rate of success with a single thoracentesis is relatively low, pleuroamniotic shunt, consisting of a permanent communication between the pleural space and the amniotic cavity, has been proposed as first-line treatment in primary severe fetal hydrothorax (43-45) (Fig. 3).

Although no randomized trials comparing different interventions for fetal pleural effusion have been performed, data from retrospective analysis of large case series suggest pleuroamniotic shunting as a more effective treatment compared to repeated thoracocente- sis for hydropic fetuses. Despite the good level of tolerance by both mother and fetus, shunt placement is burdened by several complications: immediate fetal demise following shunt placement has been reported up to $11 \%$ (39). Shunt dislocation varies from $20 \%$ to $65 \%$ among studies and is sometimes associated with a lateral or antero-lateral shunt insertion (Fig. 4). Preterm delivery and premature rupture of membranes remains a common complication of prenatal intervention with a survival rate of $66 \%$ in premature birth and $100 \%$ in full-term delivery $(16,46,47)$.

Chest wall deformity has been described as a complication of thoracoamniotic shunt placement, especially if performed before 20 weeks of gestation (48). Interval between thoracoamniotic shunting and birth appears to be crucial; the longer the interval, the more likely is the reversal of antenatal hydrops and subsequent neonatal survival (28).

Recently, intrauterine pleurodesis with OK-432, a sclerosant commonly used in adults and children with lymphangioma, has been shown to be effective in fetuses with early hydrothorax ( $<21$ weeks gestation), and it may 
TABLE 2

\section{Diagnostic Procedures Suggested in Fetal Hydrothorax}

\begin{tabular}{|c|c|c|}
\hline Examinations & Comments & References \\
\hline $\begin{array}{l}\text { Detailed maternal } \\
\text { history }\end{array}$ & $\begin{array}{l}\text { - Ethnicity and risk of specific genetic disorders (e.g. } \\
\text { hemoglobinopaties) } \\
\text { - Underlying pathologies (e.g. collagen-vascular } \\
\text { diseases, organ transplant, disthyroidisms, blunt } \\
\text { abdominal trauma, viral infections, jaundice in other } \\
\text { family members) } \\
\text { - Medications and exposure to teratogenic substances } \\
\text { - Previous pregnancies (e.g. genetic or chromosomal } \\
\text { abnormalities, inborn errors of metabolism, congenital } \\
\text { malformations, jaundice, congenital heart defects, fetal } \\
\text { demise, polyhydramnios). }\end{array}$ & $(103)(104)$ \\
\hline Maternal blood testing & $\begin{array}{l}\text { - Blood cell count } \\
\text { - blood group and Rh (plus the partner's one if } \\
\text { available) } \\
\text { - Hb electrophoresis, erythrocyte enzymes (G6PD, } \\
\text { pyruvate kinase, and glucose phosphate isomerase) } \\
\text { - Kleihauer-Betke test } \\
\text { - serum alpha-fetoprotein } \\
\text { - anti-SSA/SSB antibodies } \\
\text { - toxoplasma gondii, rubella virus, cytomegalovirus, } \\
\text { herpes simplex virus, enterovirus, syphilis, varicella- } \\
\text { zoster virus, Lyme disease, HIV, parvovirus B19 } \\
\text { - Genetic testing for inborn error of metabolism }\end{array}$ & $(105)(106)$ \\
\hline Fetal imaging & $\begin{array}{l}\text { - Detailed morphologic obstetric ultrasound study in a } \\
\text { tertiary center (assessment of the fetal venous and } \\
\text { arterial circulations, venous and arterial MCA } \\
\text { Doppler) } \\
\text { - Fetal echocardiogram } \\
\text { - Exclude Twin-to-twin transfusion syndrome } \\
\text { - Fetal MRI }\end{array}$ & $(107)(108)$ \\
\hline Amniocentesis & $\begin{array}{l}\text { - Karyotype } \\
\text { - Chromosomal microarray } \\
\text { - Inborn errors of metabolism gene mutations } \\
\text { - Culture/PCR for infective agents (where indicated, } \\
\text { based on maternal serology) } \\
\text { - DNA extraction for alpha-thalassemia }\end{array}$ & $(109)(110)$ \\
\hline $\begin{array}{l}\text { Fetal blood testing } \\
\text { (in case of concomitant } \\
\text { intrauterine transfusion) }\end{array}$ & $\begin{array}{l}\text { - Karyotype } \\
\text { - Fetal complete blood count } \\
\text { - Hemoglobin electrophoresis } \\
\text { - Congenital infections } \\
\text { - Fetal albumin } \\
\text { - Inborn errors of metabolism assessment* }\end{array}$ & $(111)(112)$ \\
\hline
\end{tabular}

*Hydrops fetalis has been described in lysosomal storage diseases including Gaucher disease type II, Morquio disease, Hurler syndrome, Sly syndrome, Farber disease, GM1 gangliosidosis, I-cell disease, Niemann-Pick disease type $\mathbf{A}$ and type $\mathbf{C}$, infantile sialic acid storage disorder, alphaneuroaminidase deficiency, multiple sulfatase deficiency, and Wolman disease. Consider also nonlysosomal diseases, including glycogenosis type IV, long-chain hydroxy-acylCoA dehydrogenase deficiency, CDG type1a, CDG type I/IX, hypothyroidism, Carnitine deficiency, and Smith-Lemli-Opitz syndrome 

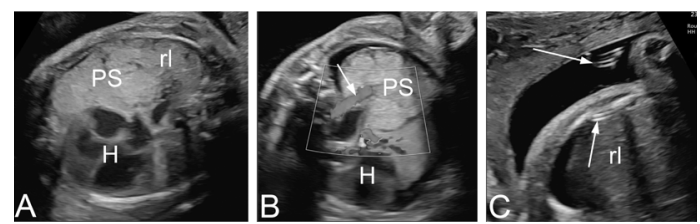

Fig. 3. The same fetus as in Figure 1 with pulmonary sequestration complicated by severe hydrothorax treated with thoraco-amniotic shunt. A: pleural effusion is completely drained into the amniotic fluid. The right lung $(\mathrm{rl})$, the heart $(\mathrm{H})$, and pulmonary sequestration (PS) are visible; B: Color Doppler imaging shows the vascular pedicle with the afferent artery originating from the thoracic aorta (arrow); $C$ : correct position of the thoraco-amniotic shunt with one end visible in the pleural space and the other within amniotic cavity (arrows).

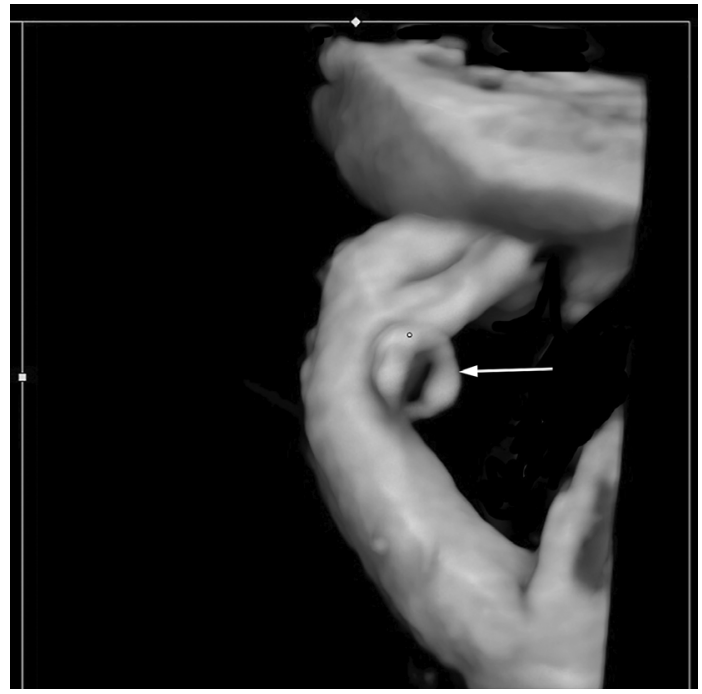

Fig. 4. A three-dimensional reconstruction of a shunt extremity (white arrow) surrounded by a fetal arm in a case of a 30+3 week fetus with hydrothorax treated with a thoraco-amniotic shunt laterally inserted. The shunt appeared to be dislocated and tightened in the fetal hand at the follow-up ultrasound scan evaluation.

reduce the risk of premature membrane rupture associated with prenatal intervention as the needle needed for injection is considerably thinner (49,50). Although promising, further studies are needed to assess efficacy and safety of this procedure.

Maternal dietary treatment with a low-fat, high medium-chain triglyceride diet has been suggested to reduce the amount of pleural fluid accumulation in cases of fetal chylothorax, delaying the need for thoracentesis (51). It may be considered both in conservative management and in combination with surgical treatment (52).

\section{POST-NATAL DIAGNOSIS OF CONGENI- TAL CHYLOTHORAX}

Most cases of congenital chylothorax are detected prenatally, however fluid drainage is mandatory to confirm the chylous nature of pleural effusion. In newborns enterally fed, a milky white opalescent appearance of drained fluid is suggestive of chylous effusion. The presence of an effusion/serum protein ratio of 0.5 or more, effusion LDH $>160$ IU/L and effusion $\mathrm{pH}<7.4$ is suggestive of exudate, and the lymphatic origin of pleural fluid is confirmed by the presence of chylomicra and triglycerides $>110 \mathrm{mg} / \mathrm{dl}(1.24 \mathrm{mmol} / \mathrm{L})$ and absolute cell count $>1,000$ per $\mathrm{mL}$ with a lymphocyte fraction $>80 \%$ in exudate cases $(53,54)$.

Once the presence of chylothorax is confirmed after birth, diagnostic work-up should be performed to find the etiology and establish a targeted therapy when available (55). A diagnostic flow-chart is proposed in Fig. 5.

A meticulous blood examination panel, customized in accordance with the diagnostic hypotheses, should be performed soon after birth, while imaging studies are necessary to evaluate cardiopulmonary, thoracic and cerebral anatomy and function (Fig. 6).

Karyotype and specific genetic mutation analysis are mandatory in case a syndromic or genetic condition is suspected (Table 3). Lung biopsy with subsequent histological and immunohistochemical studies should be performed to confirm the diagnosis of congenital pulmonary lymphangiectasia (56).

In addition, lymphatic system imaging procedures are often needed to outline abnormal lymphatic drainage patterns and to identify the site of chyle leakage. Many techniques have been proposed to investigate 


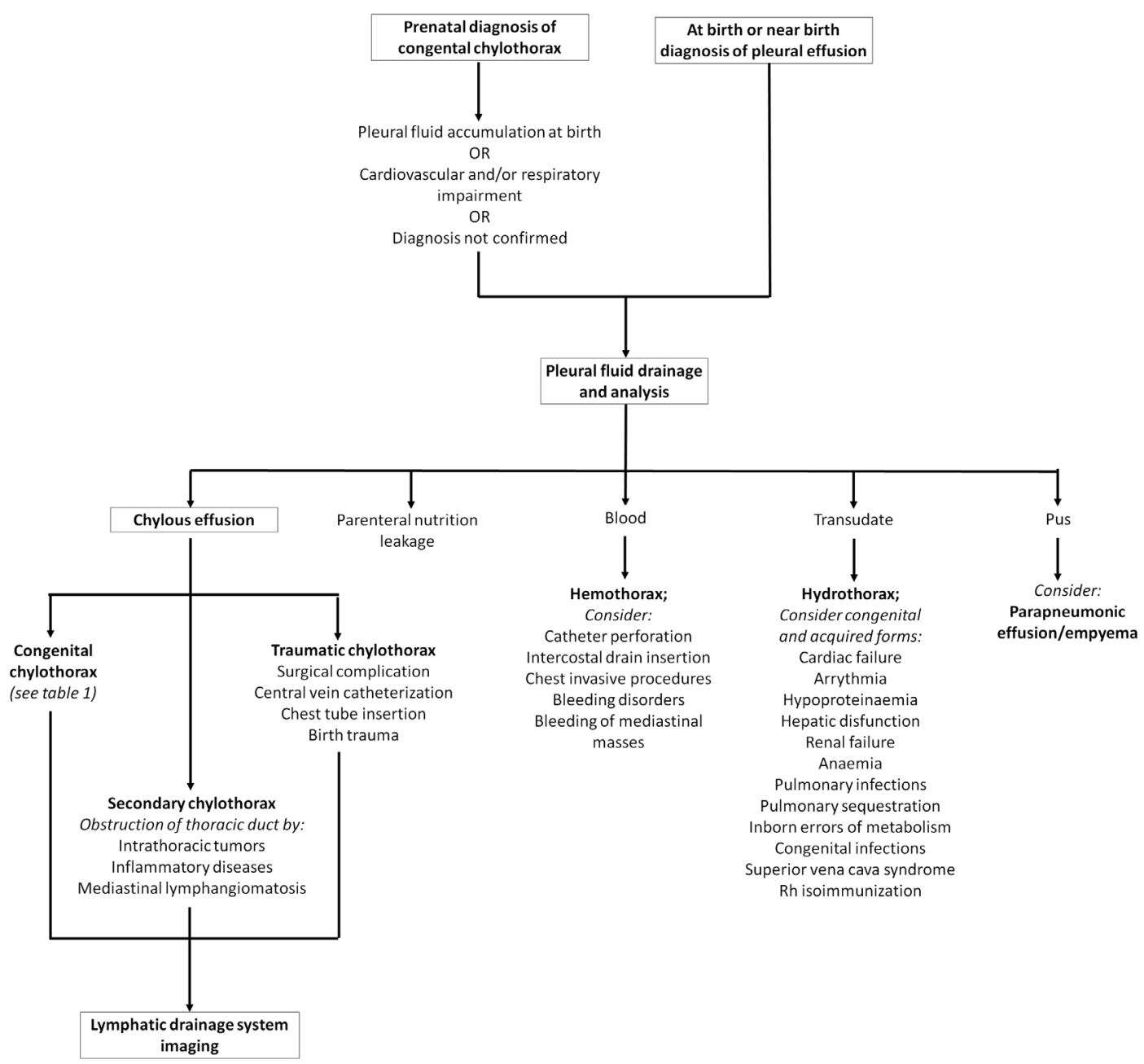

Fig. 5. Diagnostic algorithm of the management of neonatal pleural effusion detected prenatally or after birth.

anatomy and function of both central conducting lymphatics, including retroperitoneal lymphatic channels, cisterna chyli, and thoracic duct as well as peripheral lymphatic vessels, although no standardized procedure has yet been established in newborns and infants (57). Key diagnostic techniques are summarized in Table 4.

In case of prenatal etiological diagnosis and complete or nearly complete resolution of pleural effusion due to in utero treatment, associated with clinically stable cardiovascular and respiratory conditions, conservative management and close follow-up may be cautious- ly considered during the neonatal period (41). When pleural effusion is detected at birth or near birth, fluid drainage must be performed both for diagnostic and therapeutic purposes, and acquired causes of chylothorax should be considered.

\section{MANAGEMENT OF POST-NATAL CON- GENITAL CHYLOTHORAX}

Post-natal management of congenital chylothorax is challenging, both for the heterogeneity of clinical course and because the optimal treatment has not been established de- 


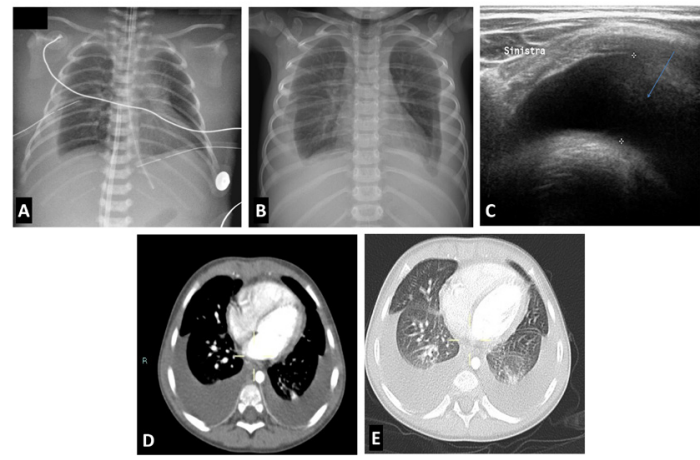

Fig. 6. Chest imaging techniques to assess the presence and severity of pleural effusion.

A: Presence of bilateral thoracic drainage with satisfactory lung expansion. Mild right pleural effusion; B: subsequent control 24 hours after thoracic drainage removal shows bilateral effusion associated with vascular and interstitial congestion; C: ultrasonographic appearance of pleural hypoechoic effusion in a transverse section of the left hemithorax; D, E: axial sections of contrast computed tomography imaging showing bilateral pleural effusion and vascular congestion; (D) parenchymal and $(E)$ mediastinal windows.

spite the wide variety of available treatments. A post-natal therapeutic algorithm currently used in the Gaslini Unit is suggested in Fig. 7.

Perinatal asphyxia and respiratory insufficiency are major symptoms of congenital chylothorax at birth, especially in cases of severe pleural effusion and/or hydrops, and vigorous resuscitation is frequently necessary soon after birth (58). Thoracocentesis performed in the delivery room may guarantee an adequate lung expansion while intubation and mechanical ventilation may improve respiratory function.

Once the neonate is admitted in the neonatal intensive care unit, supportive management consists of respiratory and cardiovascular support, pleural drainage, nutritional management and pain therapy.

While both conventional and high frequency ventilation have been employed in infants with pleural effusion without conclusive data regarding the superiority of one modality or another, the latter may improve

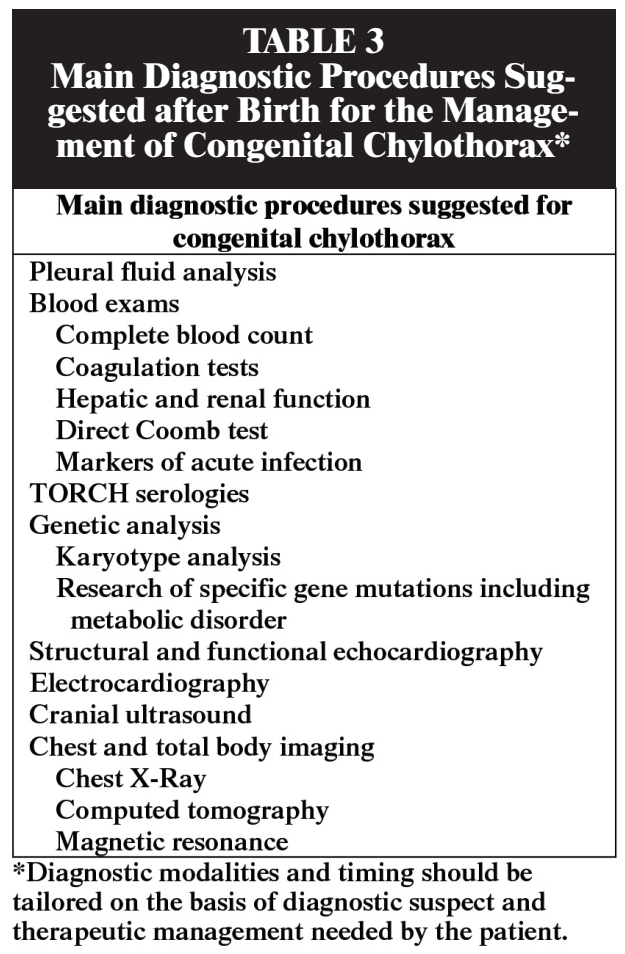

lung opening and volume maintenance, which may prevent further pleural fluid accumulation $(59,60)$. Together with fluid and electrolyte replacement, transfusion with fresh frozen plasma or albumin should be considered in order to maintain an adequate oncotic pressure in the blood vascular compartment as hypoproteinaemia can frequently occur in these patients.

Neonates with prolonged pleural effusion congenital chylothorax are at higher risk of infection, due to both hypogammaglobulinemia and leukopenia, and may benefit from intravenous immunoglobulin infusion (30).

\section{Nutritional Management}

The aim of nutritional therapy is to minimize intestinal lymphatic flow, both by using the parenteral route for feeding and by modifying the fat content of enteral feeds. Total parenteral nutrition may be indicated in case 


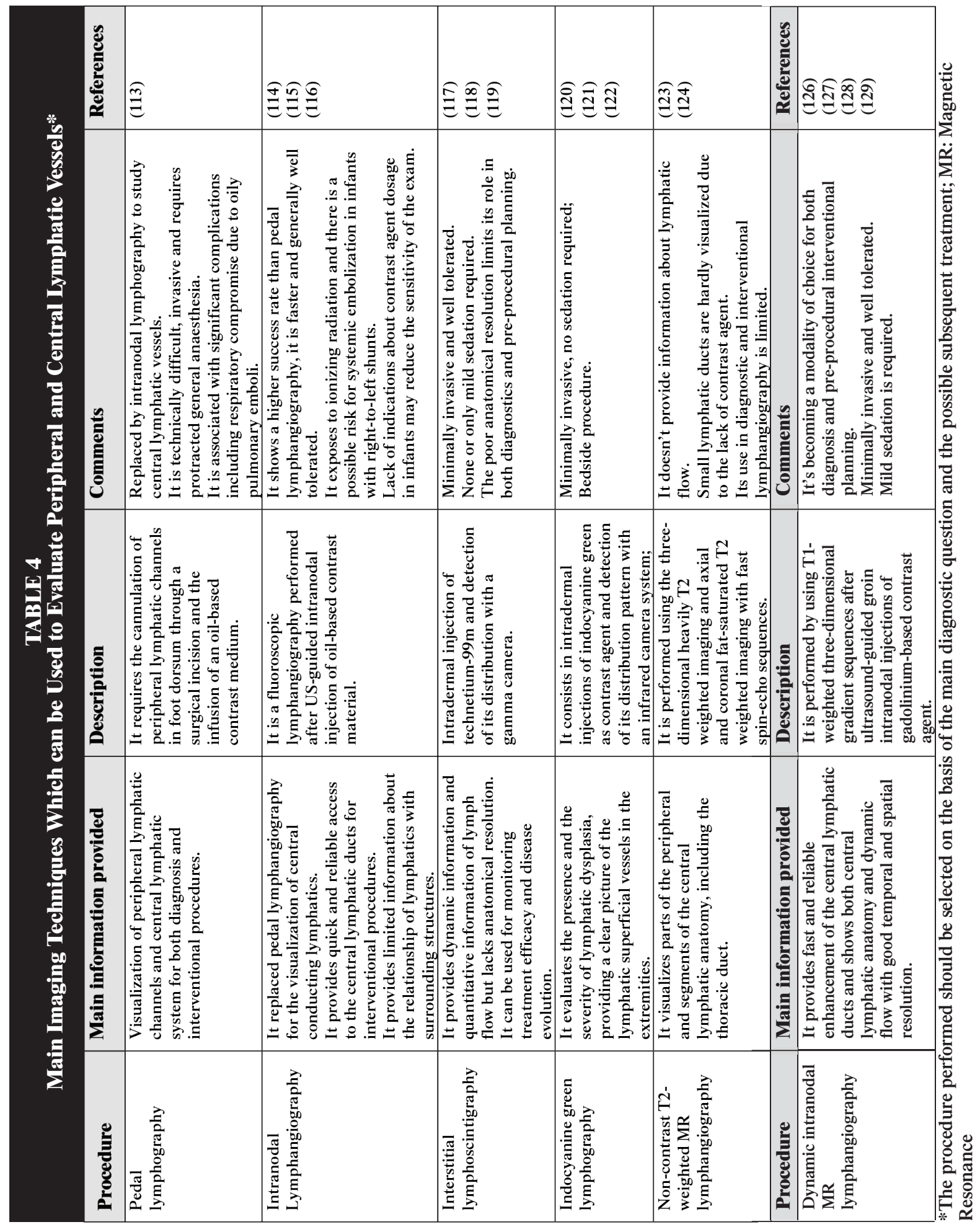




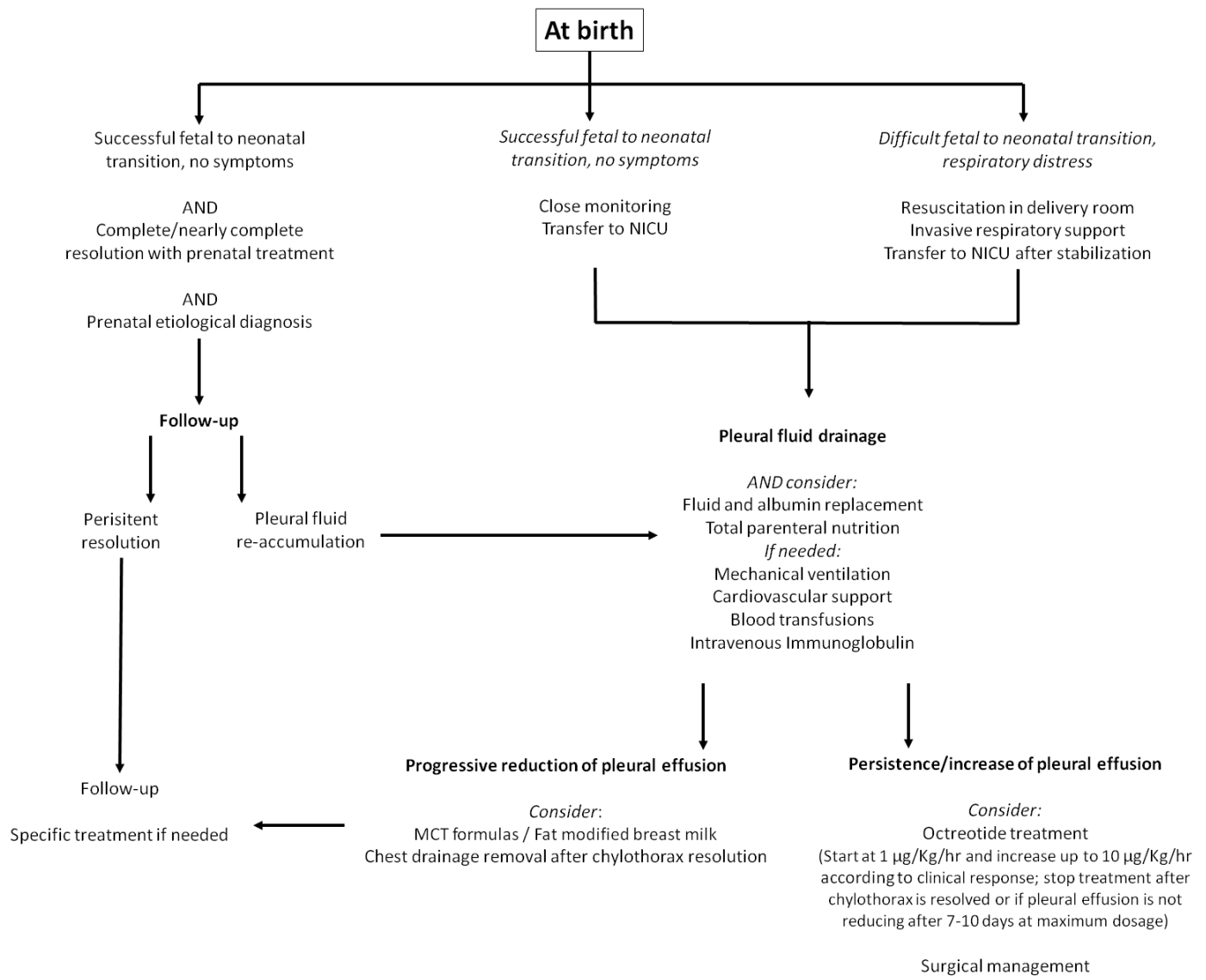

Fig. 7. Neonatal management algorithm for congenital chylothorax. MCT: medium chain triglycerides; NICU: Neonatal Intensive Care Unit. Modified from Bellini et al. 2016 (55).

of progressive and severe chylothorax or in intubated neonates (61) while medium chain triglyceride (MCT) formulas or fat modified breast milk have been shown to be effective in patients who can be orally fed $(62,63)$. MCTs are directly absorbed into the portal venous system, drastically reducing both the fat content and volume of chylous effusion.

Infants who are fed with fat-modified breast milk may require additional fortification to support adequate growth (64).

\section{Treatment with Octreotide}

Octreotide, a somatostatin analogue, reduces lymphatic flow by causing mild vasoconstriction of splanchnic vessels, inhibits gastric, pancreatic, and intestinal secretions, and also reduces hepatic venous flow and intestinal absorption, which decrease the hydrostatic pressure driving chylous flow (65). Although octreotide is currently used as an additional treatment in neonatal congenital and post-operative chylothorax, no consensus has been reached on its use due to the lack of evidence about its efficacy and safety (66). Octreotide is usually administered as a second-line treatment after total parenteral nutrition failure and before considering surgical treatment. Marked variation among studies in octreotide regimen is reported, the commonest being intravenous infusion at a starting dose of 1 $\mu \mathrm{g} / \mathrm{Kg} / \mathrm{hr}$, gradually increasing to $10 \mu \mathrm{g} / \mathrm{Kg} / \mathrm{hr}$ according to therapeutic response. Although 
heterogeneous definitions of octreotide efficacy have been reported, it generally refers to a significant reduction in chylous effusion within two weeks of drug administration. Octreotide has been reported to be effective in $47 \%$ of neonates with chylothorax from any cause with a slightly higher effectiveness in congenital forms and with a low incidence of side effects (67). Concerns remain about the possible onset of pulmonary hypertension and necrotizing enterocolitis in association with octreotide treatment (68-70). In addition, one case of severe hypotension following intravenous octreotide administration has been reported (71).

\section{Other Emerging Medical Treatments}

Sirolimus, also called rapamycin, is a macrolide compound naturally produced by several actinomycetes, possessing immunosuppressive, cytostatic, and antiproliferative properties (72). It inhibits the mammalian target of rapamycin (mTOR), a serine/threonine kinase which promotes cell growth, proliferation and survival $(73,74)$. Besides its immunosuppressive and anti-neoplastic effects, sirolimus has played a role in treating lymphatic malformations through the inhibition of lymphangiogenesis secondary to decreased synthesis and augmented degradation of vascular endothelial growth factor (VEGF) receptor 3 (75). Only a few cases of lymphatic malformations treated with sirolimus in infants have been reported to date but based on published data most patients have shown at least a partial response with minor adverse effects (76). Although dose and duration of treatment in neonates and small children still remains to be determined, treatment with sirolimus may represent a promising therapeutic option in case of extensive lymphatic malformations associated with chylothorax $(77,78)$.

Sildenafil is a selective inhibitor of phosphodiesterase type 5 , which is responsible for cyclic guanosine monophosphate (cGMP) degradation. In the neonatal setting, it is a therapeutic option for the treatment of pulmonary arterial hypertension as cGMP accumulation leads to smooth muscle relaxation and vasodilation of the pulmonary vasculature (79).

Recently sildenafil has been proposed as a novel treatment for severe lymphatic malformations in children as lymphatic vessel growth and function is partly regulated by nitric oxide-induced production of cGMP, which is thought to facilitate lymphatic endothelial cell proliferation, migration and vessel formation $(80-82)$. Since sildenafil prevents the degradation of cGMP, it may promote lymphatic vessel growth and/or remodeling, leading to a resolution of lymphatic obstruction and chylothorax. In 2015 oral sildenafil was reported to be effective for the first time in a case of a late preterm infant with chylothorax associated with congenital pulmonary lymphangiectasia (83). However, further evidence is needed both in the laboratory and the clinical setting before this treatment can be considered.

\section{Chemical Pleurodesis}

Chemical pleurodesis is performed by injecting substances into the pleural space which cause fibrous adhesions between the visceral and parietal pleura. Pleurodesis with povidone-iodine has been shown to be effective in $58-80 \%$ of neonates with chylothorax refractory to other medical treatments $(71,84,85)$, but it has been associated with a number of complications including acute and chronic renal failure, hyperthyroidism, respiratory distress and cardiorespiratory failure (84). For these reasons its use in newborn infants should be cautiously considered (86).

Pleurodesis with intrapleural injection of OK-432 has been successfully attempted postnatally in a few infants with refractory chylothorax and although it seems to be safe and well tolerated (87-88), one case of life-threatening haemolytic anemia has been recently reported in a late preterm infant with persistent left chylothorax who received two doses of intrapleural OK-432 (89).

\section{Surgical Management}


Surgical treatment is usually reserved for infants with refractory chylothorax, defined as massive chyle leak (more than $50 \mathrm{~mL} / \mathrm{kg}$ / day), or leak persistence, metabolic/nutritional complications, or overall clinical deterioration in spite of conservative treatment $(5,90)$. While in post-surgical chylothorax, caused by iatrogenic rupture of thoracic duct, the more frequently chosen intervention is duct ligation as a surgical option (91), congenital chylothorax may pose more questions about about the choice of surgical approach. As no guidelines exist on operative management of congenital chylothorax and different options are available to treat this condition, optimal timing and type of surgical intervention should be evaluated according to such factors as age and size of the infant, severity of chylous leak, center specific surgical preference and length of attempted conservative management (92).

Pleuroperitoneal shunt has been reported to be an effective and well tolerated procedure in both term and preterm infants, yet the duration of shunt placement usually lasts from weeks to months. The external component is a potential source of infection, and obstruction or malfunctioning may require a further surgical intervention $(93,94)$.

Mechanical pleurodesis is performed by gentle abrasion of the pleura to induce obliteration of the pleural space and may be performed both via thoracotomy and thoracoscopy. It has been demonstrated to be effective and safe in treating refractory chylothorax in infants, with a mean duration of post-operative chest tube drainage of nearly one week which allows a more rapid hospital discharge. However follow-up studies are needed to assess long term consequences of loss of sliding between the pleura and the lung $(92,95)$.

Percutaneous thoracic duct embolization, consisting in a transcatheter embolization of the duct proximal to the chyle leak, is a less invasive procedure than thoracic duct ligation and has gained interest after intranodal lymphangiography replaced the more hazardous and technically difficult pedal lymphangiography (96). Small infant case series have shown this technique to be successful where conservative treatment and duct ligation have failed (97-99).

Thoracoscopic parietal pleural clipping has been successfully attempted in infants with refractory chylothorax in whom visualization of the thoracic duct and lymphatics was not possible (100).

Diaphragmatic fenestration, consisting of a circular excision of a portion of the diaphragm subsequently sutured to a fenestrated polytetrafluoroethylene patch, has been recently performed in a small cohort of infants with persistent chylothorax following cardiac surgery and shows promising results in terms of efficacy and safety (101).

Lymphovenous anastomosis is a new microsurgical technique in this setting consisting of an end-to-end or end-to-side thoracic duct-venous anastomosis through either transabdominal catheterization or percutaneous groin lymphatic access. It can rapidly restore a physiological lymphatic circulation, and it has recently been successfully attempted in two infants who failed traditional medical management and were unable to undergo alternative interventions (102).

\section{FUTURE DIRECTIONS}

Congenital chylothorax is a rare but severe condition with an elevated prenatal and postnatal morbidity and mortality. The heterogeneity of underlying etiology and the high variability of clinical manifestations make its diagnostic and therapeutic management challenging, both in the prenatal and in the neonatal period.

Fetal hydrothorax is the result of several conditions which vary in pathophysiology and clinical outcomes. Therefore an accurate diagnostic work-up is mandatory in order to determine the etiology and establish the subsequent treatment strategy. As no definite consensus exists on hydrothorax management, for every case a careful evaluation of potential options should be performed.

Different conservative approaches have 
been proposed to treat this condition in the neonatal period, and several surgical options have been attempted with variable level of success and safety profile. Aside from supportive therapies, conservative treatments consist in dietary management including total parenteral nutrition, MCT formulas or fat-modified breast milk, treatment with octreotide and chemical pleurodesis. In some cases, dietary management alone is effective with a complete resolution of the chyle leak, but the persistence and the increase of pleural effusion necessitate additional treatment options.

Intravenous octreotide is extensively used regardless of chylothorax etiology as a second-line treatment after nutritional intervention failure and before considering a surgical management. Despite its extensive use, there is a wide variation in the treatment dose, duration and efficacy among the reported studies, and no consensus exists on optimal regimen or specific patient subgroups that could benefit most from the treatment. Conflicting reports also exist about efficacy and safety of chemical pleurodesis with povidone-iodine while a novel technique consisting of intrapleural injection of OK-432 has been successfully attempted even though safety needs to be further evaluated.

Recently, sirolimus has gained interest in the treatment of lymphatic malformations and although very few data exist on its application in the neonatal period, it seems to be a promising therapeutic option in selected cases in which congenital chylothorax is associated with extensive lymphatic malformations.

Surgical treatment is performed after a variable period in which conservative treatment turns out to be ineffective. New microsurgical and minimally invasive procedures have shown excellent results with a faster disease resolution and good safety profile but larger cohorts of patients are needed to confirm efficacy.

Although there is an urgent need to identify the optimal prenatal and post-natal management of congenital chylothorax, prospective multicentric trials involving a large sample size are hardly feasible due to the rarity of the condition and the heterogeneity of both presentation and etiology.

At the same time, published case reports and case series often lack detailed information about treatment regimen and duration, and efficacy is frequently scantly defined especially for conservative treatment. To enhance levels of evidence regarding congenital chylothorax management, we suggest continuing and meticulous case reports allowing improved comparison in systematic reviews. Finally, we believe shared diagnostic and therapeutic management between Neonatology Divisions and Fetal Medicine Services is of paramount importance to accelerate post-natal diagnostic work-up and select the most suitable and patient specific treatment plan.

\section{CONFLICT OF INTEREST AND DISCLO- SURE}

The authors declare no competing financial interests exist.

\section{REFERENCES}

1. Bellini, C, F Boccardo, E Bonioli et al:

Lymphodynamics in the fetus and newborn. Lymphology 39 (2006), 110-117.

2. Hansen, KC, A D'Alessandro, CC Clement et al: Lymph formation, composition and circulation: A proteomics perspective. Int. Immunol. 27 (2015), 219-227.

3. Cooper, LJ, JP Heppell, GF Clough, et al: An image-based model of fluid flow through lymph nodes. Bull. Math Biol. 78 (2016), 52-71.

4. Bellini, C, Z Ergaz, F Boccardo, et al: Dynamics of pleural fluid effusion and chylothorax in the fetus and newborn: Role of the lymphatic system. Lymphology 46 (2013), 75-84.

5. Downie, L, A Sasi, A Malhotra: Congenital chylothorax: Associations and neonatal outcomes. J. Paediatr. Child Health 50 (2014), 234-238.

6. Bialkowski, A, CF Poets, AR Franz, et al: Congenital chylothorax: A prospective nationwide epidemiological study in Germany. Arch. Dis. Child Fetal Neonatal Ed. 100 (2015), F169172.

7. Bellini, C, RC Hennekam, F Boccardo, et al: 
Nonimmune idiopathic hydrops fetalis and congenital lymphatic dysplasia. Am. J. Med. Genet. A. 140 (2007), 678-684.

8. Brock, WW, WT Bradshaw: Congenital Chylothorax: A unique presentation of nonimmune hydrops fetalis in a preterm infant. Adv. Neonatal Care. 16 (2016), 114-123.

9. Bellini, C, M Mazzella, C Campisi, et al: Multimodal imaging in the congenital pulmonary lymphangiectasia-congenital chylothorax-hydrops fetalis continuum. Lymphology 37 (2004), 22-30.

10. Rocha, G, P Fernandes, P Rocha, et al: Pleural effusions in the neonate. Acta Paediatr. 95 (2006), 791-798.

11. Faul, JL, GJ Berry, TV Colby, et al: Thoracic lymphangiomas, lymphangiectasis, lymphangiomatosis, and lymphatic dysplasia syndrome. Am. J. Respir. Crit. Care Med. 161 (2000), 1037-1046.

12. Römer, S, B Opgen-Rhein, R Chaoui, et al: Bilateral agenesis of the superior vena cava associated with congenital hydrothorax. Ultrasound Obstet. Gynecol. 28 (2006), 842-844.

13. Bellini, C, M Mazzella, C Arioni, et al: Hennekam syndrome presenting as nonimmune hydrops fetalis, congenital chylothorax, and congenital pulmonary lymphangiectasia. Am. J. Med. Genet. A. 120 (2003), 92-96.

14. Bellini, C, F Boccardo, C Campisi C, et al: Congenital pulmonary lymphangiectasia. Orphanet J. Rare Dis. 1 (2006), 43.

15. Castagno, R, E Carreras, N Toran, et al: Fetal pleural effusion. DSJUOG 1 (2007), 28-39.

16. Rustico, MA, M Lanna, D Coviello, et al: Fetal pleural effusion. Prenat. Diagn. 27 (2007), 793799.

17. Yinon, Y, E Kelly, G Ryan: Fetal pleural effusions. Best Pract. Res. Clin. Obstet. Gynaecol. 22 (2008), 77-96.

18. Bellini, C, RC Hennekam: Clinical disorders of primary malfunctioning of the lymphatic system. Adv. Anat. Embryol. Cell Biol. 214 (2014), 187-204.

19. Kim, SA, SM Lee, JS Hong, et al: Ultrasonographic severity scoring of non-immune hydrops: A predictor of perinatal mortality. J. Perinat. Med. 43 (2015), 53-59.

20. Aubard, Y, I Derouineau I, V Aubard, et al: Primary fetal hydrothorax: A literature review and proposed antenatal clinical strategy. Fetal Diagn. Ther. 13 (1998), 325-333.

21. Klam, S, JL Bigras, L Hudon: Predicting outcome in primary fetal hydrothorax. Fetal Diagn. Ther. 20 (2005), 366-370.

22. Trocadoa V, JP Coutinho-Borgesa, M Carlos-Alvesa: Fetal primary hydrothorax with spontaneous resolution. Case Reports in Women's Health 15 (2017), 6-7.

23. Weber, AM, EH Philipson: Fetal pleural effusion: A review and meta-analysis for prognostic indicators. Obstet. Gynecol. 79 (1992), 281-286.

24. Longaker, MT, JM Laberge, J Dansereau, et al: Primary fetal hydrothorax: Natural history and management. J Pediatr. Surg. 24 (1989), 573-576.

25. Ota, S, J Sahara, A Mabuchi, et al: Perinatal and one-year outcomes of non-immune hydrops fetalis by etiology and age at diagnosis. J. Obstet. Gynaecol. Res. 42 (2016), 385-391.

26. Wada, S, SC Jwa, Y Yasuo, et al: The prognostic factors and outcomes of primary fetal hydrothorax with the effects of fetal intervention. Prenat. Diagn. 37 (2017), 184-192.

27. Ruano, R, AS Ramalho, AK Cardoso, et al: Prenatal diagnosis and natural history of fetuses presenting with pleural effusion. Prenat. Diagn. 31 (2011), 496-499.

28. Dorsi, M, A Giuseppi, F Lesage: Prenatal factors associated with neonatal survival of infants with congenital chylothorax. J. Perinatol. 38 (2018), 31-34.

29. Bellini, C, Z Ergaz, M Radicioni, et al: Congenital fetal and neonatal visceral chylous effusions: Neonatal chylothorax and chylous ascites revisited. A multicenter retrospective study. Lymphology 45 (2012), 91-102.

30. Wasmuth-Pietzuch, A, M Hansmann, P Bartmann, et al: Congenital chylothorax: lymphopenia and high risk of neonatal infections. Acta Paediatr. 93 (2004), 220-224.

31. Bellini, C, G Donarini, D Paladini, et al: Etiology of non-immune hydrops fetalis: An update. Am J. Med. Genet. A 167 (2015), 1082-1088.

32. Bellini, C, RC Hennekam: Non-immune hydrops fetalis: A short review of etiology and pathophysiology. Am. J. Med. Genet. Part A 158A (2012), 597-605.

33. Bellini, C, RC Hennekam, E Bonioli: A diagnostic flow chart for non-immune hydrops fetalis. Am. J. Med. Genet. A 149 (2009), 852853.

34. Lee, CJ, PN Tsao, CY Chen, et al: Prenatal Therapy improves the survival of premature infants with congenital chylothorax. Pediatr. Neonatol. 57 (2016), 127-132.

35. Lee, CJ, PN Tsao, CY Chen, et al: Prenatal therapy improves the survival of premature infants with congenital chylothorax. Pediatr. Neonatol. 57 (2016), 127-132.

36. Carr, BD, L Sampang, JT Church, et al: Fetal intervention for congenital chylothorax is asso- 
ciated with improved outcomes in early life. $\mathbf{J}$. Surg. Res. 231 (2018), 361-365.

37. Mon, RA, MC Treadwell, DR Berman, et al: Outcomes of fetuses with primary hydrothorax that undergo prenatal intervention (prenatal intervention for hydrothorax). J. Surg. Res. 221 (2018), 121-127.

38. Petersen, S, R Kaur, JT Thomas, et al: The outcome of isolated primary fetal hydrothorax: A 10-Year Review from a Tertiary Center. Fetal Diagn. Ther. 34 (2013), 69-76.

39. Mallmann, MR, V Graham, B Rösing: Thoracoamniotic shunting for fetal hydrothorax: Predictors of intrauterine course and postnatal outcome. Fetal Diagn. Ther. 41 (2017), 58-65.

40. O'Brien, B, G Kesby, R Ogle, et al: Treatment of primary fetal hydrothorax with OK-432 (Picibanil): Outcome in 14 fetuses and a review of the literature. Fetal Diagn. Ther. 37 (2015), 259-266.

41. Lopez-Gutierrez, JC, JA Tovar: Chylothorax and chylous ascites: management and pitfalls. Semin. Pediatr. Surg. 23 (2014), 298-302.

42. Suyama, F, K Ozawa, K Ogawa et al: Fetal lung size after thoracoamniotic shunting reflects survival in primary fetal hydrothorax with hydrops. J. Obstet. Gynaecol. Res. 44 (2018), 1216-1220.

43. Xia, B, G Yu, C Hong, et al: Outcomes of severe primary fetal hydrothorax treated by prenatal intervention. Zhonghua Fu Chan Ke Za Zhi. 53 (2018), 522-527.

44. Pellegrinelli, JM, A Kohler, M Kohler, et al: Prenatal management and thoracoamniotic shunting in primary fetal pleural effusions: A single centre experience. Prenat. Diagn. 32 (2012), 467-471.

45. Picone, O, A Benachi, L Mandelbrot, et al: Thoracoamniotic shunting for fetal pleural effusions with hydrops. Am. J. Obstet. Gynecol. 191 (2004), 2047-2050.

46. Takahashi, Y, I Kawabata I, M Sumie, et al: Thoracoamniotic shunting for fetal pleural effusions using a double-basket shunt. Prenat. Diagn. 32 (2012), 1282-1287.

47. Peranteau, WH, NS Adzick, MM Boelig, et al: Thoracoamniotic shunts for the management of fetal lung lesions and pleural effusions: A single-institution review and predictors of survival in 75 cases. J. Pediatr. Surg. 50 (2015), 301-305.

48. Rodrigo, A, RA Mon, MC Treadwell, et al: Outcomes of fetuses with primary hydrothorax that undergo prenatal intervention (prenatal intervention for hydrothorax). J, Surg. Res. 221 (2018), 121-127.

49. Nørgaard, LN, U Nygaard, JA Damm, et al:
OK-432 Treatment of early fetal chylothorax: Pregnancy outcome and long-term follow-up of 14 cases. Fetal Diagn. Ther. 3 (2018), 1-7.

50. Yim, GW, JY Kwon, YW Park, et al: Successful antenatal treatment of early fetal chylothorax with OK432 pleurodesis. Korean J. Obstet. Gynecol. 52 (2009), 752-758.

51. Bartha, JL, R Comino-Delgado: Fetal chylothorax response to maternal dietary treatment. Obstet. Gynecol. 97 (2001), 820-823.

52. Chen, M, CP Chen, JC Shih, et al: Antenatal treatment of chylothorax and cystic hygroma with OK-432 in nonimmune hydrops fetalis. Fetal Diagn. Ther. 20 (2005), 309-315.

53. Staats, BA, RD Ellefson, LL Budahn, et al: The lipoprotein profile of chylous and nonchylous pleural effusions. Mayo Clin. Proc. 55 (1980), 700-704.

54. Van Straaten, HL, LJ Gerards, TG Krediet: Chylothorax in the neonatal period. Eur. J. Pediatr. 152 (1993), 2-5.

55. Bellini, C, R Cabano, T Bellini, et al: Congenital chylothorax of the newborn: Diagnosis and treatment in three pictures. Lymphology 49 (2016), 150-156.

56. Yuan, SM: Congenital pulmonary lymphangiectasia. J. Perinat. Med. 45 (2017), 1023-1030.

57. Tutor, JD: Chylothorax in infants and children. Pediatrics 133 (2014), 722-733.

58. Straaten, HLM, LJ Gerards, TG Krediet TG: Chylothorax in the neonatal period. Eur. J. Pediatr. 152 (1993), 2-5.

59. Consigli, C, A Tempera, C Alegiani, et al: Ventilation mode and outcome of premature infants with congenital chylothorax. J. Matern. Fetal Neonatal Med. 25 (2012), 1627-1630.

60. Kugelman, A, R Gonen, D Bader: Potential role of high-frequency ventilation in the treatment of severe congenital pleural effusion. Pediatr. Pulmonol. 29 (2000), 404-408.

61. Fernández Alvarez, JR, KD Kalache, EL Graŭel: Management of spontaneous congenital chylothorax: Oral medium-chain triglycerides versus total parenteral nutrition. Am. J. Perinatol. 16 (1999), 415-420.

62. Chan, GM, E Lechtenberg: The use of fat-free human milk in infants with chylous pleural effusion. J. Perinatol. 27 (2007), 434-436.

63. Biewer, ES, C Zürn, R Arnold, et al: Chylothorax after surgery on congenital heart disease in newborns and infants -risk factors and efficacy of MCT-diet. J. Cardiothorac. Surg. 13 (2010), 127.

64. Kocel, SL, J Russell, DL O'Connor: Fat-modified breast milk resolves chylous pleural effusion in infants with postsurgical chylothorax but is associated with slow growth. JPEN J. 
Parenter. Enteral. Nutr. 40 (2016), 543-551.

65. Rasiah, SV, J Oei, K Lui: Octreotide in the treatment of congenital chylothorax. J. Paediatr. Child Health. 40 (2004), 585-588.

66. Das, A, PS Shah: Octreotide for the treatment of chylothorax in neonates. Cochrane Database Syst Rev. 9 (2010), CD006388.

67. Bellini, C, R Cabano, LC De Angelis: Octreotide for congenital and acquired chylothorax in newborns: A systematic review. J. Paediatr. Child Health. 54 (2018), 840-847.

68. Mohseni-Bod, H, D Macrae, Z Slavik: Somatostatin analog (octreotide) in management of neonatal postoperative chylothorax: Is it safe? Pediatr. Crit. Care Med. 5 (2004), 356-357 .

69. Horvers, M, CF Mooij, TA Antonius: Is octreotide treatment useful in patients with congenital chylothorax? Neonatology 101 (2012), 225-231.

70. Church, JT, AG Antunez, A Dean, et al: Evidence-based management of chylothorax in infants. J. Pediatr. Surg. 52 (2017), 907-912.

71. Scottoni, F, F Fusaro, A Conforti, et al: Pleurodesis with povidone-iodine for refractory chylothorax in newborns: Personal experience and literature review. J. Pediatr. Surg. 50 (2015), 1722-1725.

72. Park, SR, YJ Yoo, YH Ban, et al: Biosynthesis of rapamycin and its regulation: Past achievements and recent progress. J. Antibiot. (Tokyo). 63 (2010), 434-441.

73. Sehgal, SN: Sirolimus: Its discovery, biological properties, and mechanism of action. Transplant Proc. 35 (2003), 7S-14S.

74. Yoo, YJ, H Kim, SR Park SR, et al: An overview of rapamycin: From discovery to future perspectives. J. Ind. Microbiol. Biotechnol. 44 (2017), 537-553.

75. Luo, Y, Liu L, Rogers D, et al: Rapamycin inhibits lymphatic endothelial cell tube formation by down-regulating vascular endothelial growth factor receptor 3 protein expression. Neoplasia 14 (2012), 228-237.

76. Wiegand, S, G Wichmann G, A Dietz: Treatment of lymphatic malformations with the mTOR inhibitor sirolimus: A systematic review. Lymphat. Res. Biol. 16 (2018), 330-339.

77. Hammer, J, E Seront, S Duez: Sirolimus is efficacious in treatment for extensive and/or complex slow-flow vascular malformations: A monocentric prospective phase II study. Orphanet. J. Rare Dis. 29 (2018), 191.

78. Ozeki, M, R Asada, AM Saito, et al: Efficacy and safety of sirolimus treatment for intractable lymphatic anomalies: A study protocol for an open-label, single-arm, multicenter, prospective study (SILA). Regen. Ther. 10 (2019), 84-91.
79. Abman, SH, G Hansmann, SL Archer, et al: Pediatric Pulmonary Hypertension: Guidelines From the American Heart Association and American Thoracic Society. Circulation. 132 (2015), 2037-2099.

80. Danial, C, AL Tichy, U Tariq, et al: An open-label study to evaluate sildenafil for the treatment of lymphatic malformations. J. Am. Acad. Dermatol. 70 (2014), 1050-1057.

81. Swetman, GL, DR Berk, SS Vasanawala, et al: Sildenafil for severe lymphatic malformations. NEJM. 366 (2012), 384-386.

82. Kajiya, K, R Huggenberger, I Drinnenberg, et al: Nitric oxide mediates lymphatic vessel activation via soluble guanylate cyclase alpha1beta1-impact on inflammation. FASEB J. 22 (2008), 530-537.

83. Malleske, DT, BA Yoder: Congenital chylothorax treated with oral sildenafil: A case report and review of the literature. J. Perinatology (2015) 35, 384-386.

84. Resch, B, T. Freidl, F. Reiterer: Povidone-iodine pleurodesis for congenital chylothorax of the newborn. Arch. Dis. Child. Fetal Neonatal Ed. 101 (2016), F87-F88.

85. Borcyk, K, A Kamil, K Hagerty, et al: Successful management of extremely high-output refractory congenital chylothorax with chemical pleurodesis using $4 \%$ povidone-iodine and propranolol: A case report. Clin. Case Rep. 6 (2018), 702-708.

86. Mitanchez, D, E Walter-Nicolet, R Salomon, et al: Congenital chylothorax: What is the best strategy? Arch. Dis. Child Fetal Neonatal Ed. 91 (2006), F153-154.

87. Matsukuma, E, Y Aoki, M Sakai et al: Treatment with OK-432 for persistent congenital chylothorax in newborn infants resistant to octreotide. J. Pediatr. Surg. 44 (2009), e37-e39.

88. Kim, JE, C Lee, KI Park, et al: Successful pleurodesis with OK-432 in preterm infants with persistent pleural effusion. Korean $\mathbf{J}$, Pediatr. 55 (2012), 177-180.

89. Sze, SW, PC Ng, HS Lam: Life-threatening hemolytic anemia after intrapleural instillation of OK-432 for treatment of congenital chylothorax. Neonatology 110 (2016), 303-306.

90. Cleveland, K, D Zook, K Harvey, et al: Massive chylothorax in small babies. J. Pediatr. Surg. 44 (2009), 546-550.

91. Costa, KM, AK Saxena: Surgical chylothorax in neonates: Management and outcomes. World J. Pediatr. 14 (2018), 110-115.

92. Le Nué, R, F Molinaro, C Gomes-Ferreira, et al: Surgical management of congenital chylothorax in children. Eur. J. Pediatr. Surg. 20 (2010), 307-311. 
93. Engum, SA, FJ Rescorla, KW West, et al: The use of pleuroperitoneal shunts in the management of persistent chylothorax in infants. J. Pediatr. Surg. 34 (1999), 286-290.

94. Wolff, AB, ML Silen, ER Kokoska, et al: Treatment of refractory chylothorax with externalized pleuroperitoneal shunts in children. Ann. Thorac. 68 (1999), 1053-1057.

95. Cleveland, K, D Zook, K Harvey, et al: Massive chylothorax in small babies. J. Pediatr. Surg. 44 (2009), 546-550.

96. Itkin, M, G Krishnamurthy, MY Naim, et al: Percutaneous thoracic duct embolization as a treatment for intrathoracic chyle leaks in infants. Pediatrics 128 (2011), e237-41.

97. Nadolski, G, M Itkin: Thoracic duct embolization for the management of chylothoraces. Curr. Opin. Pulm. Med. 19 (2013), 380-386.

98. Srinivasa, RN, JFB Chick, JJ Gemmete, et al: Endolymphatic interventions for the treatment of chylothorax and chylous ascites in neonates: Technical and clinical success and complications. Ann. Vasc. Surg. 50 (2018), 269-274.

99. Majdalany, BS, WA Saad, JFB Chick, et al: Pediatric lymphangiography, thoracic duct embolization and thoracic duct disruption: A single-institution experience in 11 children with chylothorax. Pediatr. Radiol. 48 (2018), 235-240.

100. Clark, ME, RK Woo, SM Johnson: Thoracoscopic pleural clipping for the management of congenital chylothorax. Pediatr. Surg. Int. 12 (2015), 1133-1137.

101. Kumar, TK, K Balduf, U Boston, et al: Diaphragmatic fenestration for refractory chylothorax after congenital cardiac surgery in infants. J. Thorac. Cardiovasc. Surg. 154 (2017), 2062-2068.

102. Weissler, JM, EH Cho, PF Koltz, et al: Lymphovenous anastomosis for the treatment of chylothorax in infants: A novel microsurgical approach to a devastating problem. Plast. Reconstr. Surg. 141 (2018), 1502-1507.

103. Bekta囚, H, Y Bülbül, S Özsu, et al: A rare cause of chylothorax: Hennekam Syndrome. Turk. Thorac. J. 16 (2015), 33-35.

104. Páez Codeso, FM, MC Morillo Domínguez, A Dorado Galindo: A rare case of chylothorax. Gorham-Stout Syndrome. Arch. Bronconeumol. 53 (2017), 640.

105. Slee, J, J Nelson, J Dickinson, et al: Yellow nail syndrome presenting as non-immune hydrops: Second case report. Am. J. Med. Genet. 93 (2000), 1-4.

106. Cardoso, D, M Tuna, M Abrantes, et al: Congenital chylothorax associated with trisomy $\mathrm{X}$. Eur. J. Pediatr. 160 (2001), 743.

107. Cremonini, G, A Poggi, R Capucci, et al: Rare case of massive congenital bilateral chylothorax in a hydropic fetus with true mosaicism 47,XXX/46,XX. J. Obstet. Gynaecol. Res. 40 (2014), 259-262.

108. Chan, PC, HC Chiu, WL Hwu: Spontaneous chylothorax in a case of cardio-facio-cutaneous syndrome. Clin. Dysmorphol. 4 (2002), 297 298.

109. Yao, LC, C Testini, D Tvorogov, et al: Pulmonary lymphangiectasia resulting from vascular endothelial growth factor-C overexpression during a critical period. Circ. Res. 114 (2014), 806-822.

110. Gupta, A, KM Naranje, A Singh, et al: Congenital chylothorax in a neonate with Cornelia de Lange Syndrome: A rare complication managed with a novel indigenously prepared milk formulation. Indian J. Pediatr. (2019) doi: 10.1007/s12098-019-02908-5.

111. Geneviève, D, E Walter, P Gorry et al: Gorlin syndrome presenting as prenatal chylothorax in a girl. Prenat. Diagn. 11 (2005), 997-999.

112. Waisayarat, J, C Suriyonplengsaeng, C Khongkhatithum, et al: Severe congenital nemaline myopathy with primary pulmonary lymphangiectasia: Unusual clinical presentation and review of the literature. Diagn. Pathol. 10 (2015), 27.

113. Witte, CL, WH Williams, MH Witte: Lymphatic imaging (editorial). Lyrnphology 26 (1993), 1111-1117.

114. Majdalany, BS, WA Saad, JFB Chick, et al: Pediatric lymphangiography, thoracic duct embolization and thoracic duct disruption: A single-institution experience in 11 children with chylothorax. Pediatr. Radiol. 48 (2018), 235-240.

115. Rajebi, MR, G Chaudry, HM Padua, et al: Intranodal lymphangiography: Feasibility and preliminary experience in children. J. Vasc. Interv. Radiol. 22 (2011), 1300-1305.

116. Nadolski, GJ, M Itkin. Feasibility of ultrasound-guided intranodal lymphangiogram for thoracic duct embolization. J. Vasc. Interv. Radiol. 23 (2012), 613-616.

117. Bellini C, F Boccardo, C Campisi, et al: Lymphatic dysplasias in newborns and children: the role of lymphoscintigraphy. J. Pediatr. 152 (2008), 587-589.

118. Bellini, C, F Boccardo, G Taddei, et al: Diagnostic protocol for lymphoscintigraphy in newborns. Lymphology 38 (2005), 9-15.

119. Yoshida, RY, S Kariya, S Ha-Kawa, et al: Lymphoscintigraphy for imaging of the lymphatic flow disorders. Tech. Vasc. Interv. Radiol. 19 (2016), 273-276.

120. Mihara, M, H Hara, J Shibasaki, et al: Indocyanine green lymphography and lymphaticov- 
enous anastomosis for generalized lymphatic dysplasia with pleural effusion and ascites in neonates. Ann. Vasc. Surg. 29 (2015), 11111122.

121. Zhu, B, EM Sevick-Muraca: A review of performance of near-infrared fluorescence imaging devices used in clinical studies. Br. J. Radiol. 88 (2015), 20140547.

122. Shibasaki, J, H Hara, M Mihara, et al: Evaluation of lymphatic dysplasia in patients with congenital pleural effusion and ascites using indocyanine green lymphography. J. Pediatr. 164 (2014), 1116-1120.

123. Laor, T, FA Hoffer, PE Burrows, et al: MR lymphangiography in infants, children, and young adults. Am. J. Roentgenology 171 (1998), 1111-1117.

124. Yu, D-X, X-X Ma, Q Wang, et al: Morphological changes of the thoracic duct and accessory lymphatic channels in patients with chylothorax: detection with unenhanced magnetic resonance imaging. Eur. Radiol. 23 (2013), 702-711.

125. Notohamiprodjo, M, M Weiss, RG Baumeister, et al: MR lymphangiography at 3.0 T: Correla- tion with lymphoscintigraphy. Radiology 264 (2012), 78-87.

126. Chavhan, GB, JG Amaral, M Temple, et al: MR lymphangiography in children: Technique and potential applications. Radiographics 37 (2017), 1775-1790.

127. Krishnamurthy, R, A Hernandez, S Kavuk, et al: Imaging the central conducting lymphatics: Initial experience with dynamic MR lymphangiography. Radiology 274 (2015), 871-878.

128. Itkin, M, GJ Nadolski: Modern techniques of lymphangiography and interventions: Current status and future development. Cardiovasc. Intervent. Radiol. 41 (2018), 366-376.

129. Dory, Y: Novel lymphatic imaging techniques. Tech. Vasc. Interv. Radiol. 19 (2016), 255-261.

Carlo Bellini, MD, PhD

Neonatal Intensive Care Unit,

Department Mother \& Child

IRCCS Gaslini

Largo G. Gaslini, 5

16147 Genoa, Italy

Tel: 0039-010-56362762

Email: carlobellini@gaslini.org 